DOI 10. 18307/2021. 0513

(C) 2021 by Journal of Lake Sciences

\title{
基于四维变分同化法的巢湖流域南汁河水质模拟
}

\author{
赖锡军 $^{1 * *}$, 何国建 ${ }^{2}$ \\ (1: 中国科学院南京地理与湖泊研究所, 流域地理学重点实验室, 南京 210008) \\ (2: 清华大学水利水电工程系,水沙科学与水利水电工程国家重点实验室, 北京 100084)
}

\begin{abstract}
摘 要: 针对河流模拟中未知不确定性源对模拟精度的影响, 以巢湖流域南淝河为研究对象, 建立了基于四维变分同化 方法的南妇河干流水质模型, 研究了含未知污染源的南淝河水质过程模拟. 模型以未知污染负荷的动态变化过程为控制 变量, 通过同化沿河不同断面的逐日水质监测数据, 识别不同河段的逐日人河污染负荷过程来实现水质过程的模拟, 改 变了常规模型模拟需提前预知并输入污染负荷的应用前提. 模拟结果表明,采用四维变分同化方法的水质模拟结果有明 显改进, 重点河段水质模拟的纳什效率系数从小于 0 提高到 0.5 以上. 识别的人河污染过程与降雨过程波动总体一致, 证 实南汁河的人河污染与降雨过程密切; 同时, 模型也可识别异常的人河负荷,提高模型对水环境问题的诊断分析能力. 该 方法可推广应用于复杂河流系统, 为巢湖等流域污染来源定量解析、水质预测预警及污染管控提供支持.
\end{abstract}

关键词: 数据同化;污染负荷; 数学模型; 南汁河; 巢湖流域

\section{Water quality modelling based on 4-dimensional variational assimilation method in the Nanfei River, Lake Chaohu Basin*}

\author{
Lai Xijun $^{1 * *} \&$ He Guojian ${ }^{2}$ \\ (1: Key Laboratory of Watershed Geographic Sciences, Nanjing Institute of Geography and Limnology, Chinese Academy of \\ Sciences, Nanjing 210008, P.R.China) \\ (2: State Key Laboratory of Hydro-science and Engineering, Department of Hydraulic Engineering, Tsinghua University, Bei- \\ jing 100084 , P.R.China)
}

\begin{abstract}
To reduce model accuracy caused by unknown uncertain pollutant sources, a water quality model based on a 4-dimensional variational assimilation method was established. Water quality modelling was conducted in the mainstream of the Nanfei River, Lake Chaohu Basin, in which water quality is highly unstable influenced by unmeasured pollutant sources. The proposed model takes the unsteady process of non-point source loads as the control variable. By assimilating the daily water quality monitoring data in different gauges along the river, the water quality process was successfully reproduced by identifying the daily pollution load process of each reach. It changes the premise that the traditional model simulation needs the right pollution load in advance. The numerical experiment shows that the results of water quality simulation using variational assimilation method are significantly improved, and the Nash efficiency coefficient of water quality simulation in key river reaches is increased from less than 0 to more than 0.5. The identified pollution process consistent with the observed rainfall process proves that the pollution into the river is closely related to the rainfall. The model can also identify some abnormal pollutant loads into the river and improve the diagnosis and analysis ability of the model for water environment problems.
\end{abstract}

Keywords: Data assimilation; pollutant load; mathematical model; Nanfei River; Lake Chaohu Basin

采用数学模型模拟河流水质过程是诊断和预测河流水环境问题的重要手段 ${ }^{[1]}$. 当前, 河流水质模型已

* 2020-11-02 收稿;2021-01-12 收修改稿.

清华大学水沙科学水利水电工程国家重点实验室及宁夏银川水联网数字治水联合研究院联合开放研究基金资助 课题( sklhse-2020-Iow08) 和国家水体污染控制与治理科技重大专项 (2017ZX07603)联合资助.

** 通信作者;E-mail:xjlai@ niglas.ac.cn. 
被广泛应用于面向流域水环境系统的科学研究、工程规划和管理决策等方面,已成为流域水环境管理不可 或缺的手段 ${ }^{[2]}$. 在应用传统的数学模型模拟和预测河流水环境过程时,需要完整的边界条件和初始条件信 息以及可靠的模型参数. 然而, 由于实际河流的复杂性, 开展河流水质模拟分析时常常难以全面收集到河流 水质初始条件和边界条件等定解资料. 特别是人河污染负荷, 因其由点面源污染综合产生, 具有过程复杂、 不确定性大等特点, 是影响水质模拟精度的重要不确定性源 ${ }^{[3]}$. 当前, 我国对于大型工业企业、污水处理厂 等大型排口有较好的监测, 可较准确地获取其排放过程, 但是对于一些小型排口、地表漫流以及地下水渗人 等, 其人河规模和位置等情况都难以准确估计. 这些缺失的或者具有高度不确定性的污染负荷数据使常规 的河流水质模型运行缺少了必要的准确可靠的输人数据, 导致常规方法不再有效. 考虑到当前河流关键断 面水质浓度有相对完整的观测资料, 值得思考如何更好地去利用这些数据, 探求河流水质模拟的新方法, 为 污染负荷缺失条件下河流水质模拟提供新的可能.

基于偏微分方程最优化控制理论的变化同化方法 ( 又称“四维变分同化”,4D-Var) ${ }^{[4]}$ 可以通过同化不同 类型观测数据, 识别模型模拟所需的时空变化参数, 改进模型动力过程模拟预测能力. 其在大气科学、海洋 科学、水文学和水力学等不同门类学科已有成功的应用 ${ }^{[5-9]}$. 不过, 采用变分同化方法开展河流水质模拟的 报道仍很少, Cho 等 $^{[10]}$ 在其地表水水质模拟数据同化的回顾论文中提到了 2 篇利用三维变分同化方法 (3DVar) 模拟一维渠道的水质输运过程 ${ }^{[11]}$ 和水库的水质模拟 ${ }^{[12]}$. 鉴于四维变分同化方法既具备同化观测数据, 又可保持物理动力规律约束的能力 ${ }^{[13-14]}$, 值得加强其在河流水质模拟中的应用研究.

南淝河位于巢湖流域西北部合肥市境内, 为城市河流, 水环境问题突出. 南淝河是巢湖的主要人湖河 流, 其水质达标是巢湖流域水污染治理的重点任务 ${ }^{[15]}$. 掌握其水环境变化过程及其人河负荷对水质的影响 是开展水环境治理的基础. 但是, 与国内城市河流类似, 其存在污染来源难以全面排查清楚等问题 ${ }^{\left[{ }^{[16]}\right.}$. 按照 常规的传统模型模拟方法, 需要提前估算污染人河负荷, 才能实现水质过程的模拟. 对于这个人河污染负荷 存在很高不确定性的河流, 若没有可靠的污染人河数据, 将不可能准确模拟其水质动态. 本文以南淝河干流 董铺水库以下城区河流水质模拟为例, 探究基于变分同化法模拟水质动力过程的性能, 为人河污染负荷缺 失或具高不确定性条件下河流水质模拟提供可选方法. 研究显示, 方法可在提升河流水质模拟精度的同时 识别不确知的人河污染负荷, 为巢湖流域等环境条件复杂的流域系统中污染定量解析、水质预测预警及污 染管控等提供重要支持.

\section{1 研究区域}

南汁河位于合肥市境内, 是巢湖重要的人河支流, 也是典型城市河流. 南淝河干流河长约 $70 \mathrm{~km}$, 发源于 江淮分水岭大潜山余脉, 从西北向东南流人董铺水库、流经合肥市主城区后于人湖口施口处汇人巢湖. 南淝 河自董铺水库大坝至人湖口施口全长 $42.0 \mathrm{~km}$, 其间依次有四里河、板桥河、二十埠河、店埠河和长乐河等支 流汇人.

南汁河所在流域多年平均降水量为 $1022 \mathrm{~mm}$. 尽管降水较为充沛, 但是由于上游董铺水库为合肥市的 主要饮用水水源,坝下游河段仍缺乏充足的清洁水源补给. 南淝河水源主要为污水处理厂处理后的生产和 生活用水的尾水, 以及区域内的城市和农村的地表径流等. 受区域密集人口及高速发展的社会经济影响, 南 淝河水质近年多处于 $\mathrm{V}$ 类和劣 $\mathrm{V}$ 类水平, 水环境问题突出. 目前, 干流计算区域内有望塘、清溪、王小虽、小 仓房 4 座污水处理厂尾水人河; 店埠河有撮镇和联禧污水处理厂尾水人河 (图 1). 其中干流望塘、清溪、王 小虽和小仓房污水处理规模总量为 110 万 $\mathrm{m}^{3} / \mathrm{d}$. 从 2019 年运行数据可知, 各个污水厂排水基本稳定, 达到 了准 IV 类水质要求.

\section{2 模型方法与构建}

\section{1 河流水质变分同化方法}

南汁河水质沿程动态变化过程可采用具有反应源项的一维物质输运方程来表达. 为了简便, 仅考虑水 体中污染物质沿河纵向的随流输移运动以及沿程的生化降解过程, 具体为:

$$
\frac{\partial C}{\partial t}+\frac{\partial}{\partial x}\left(U \cdot C-D \frac{\partial C}{\partial x}\right)=-K \cdot C+S
$$




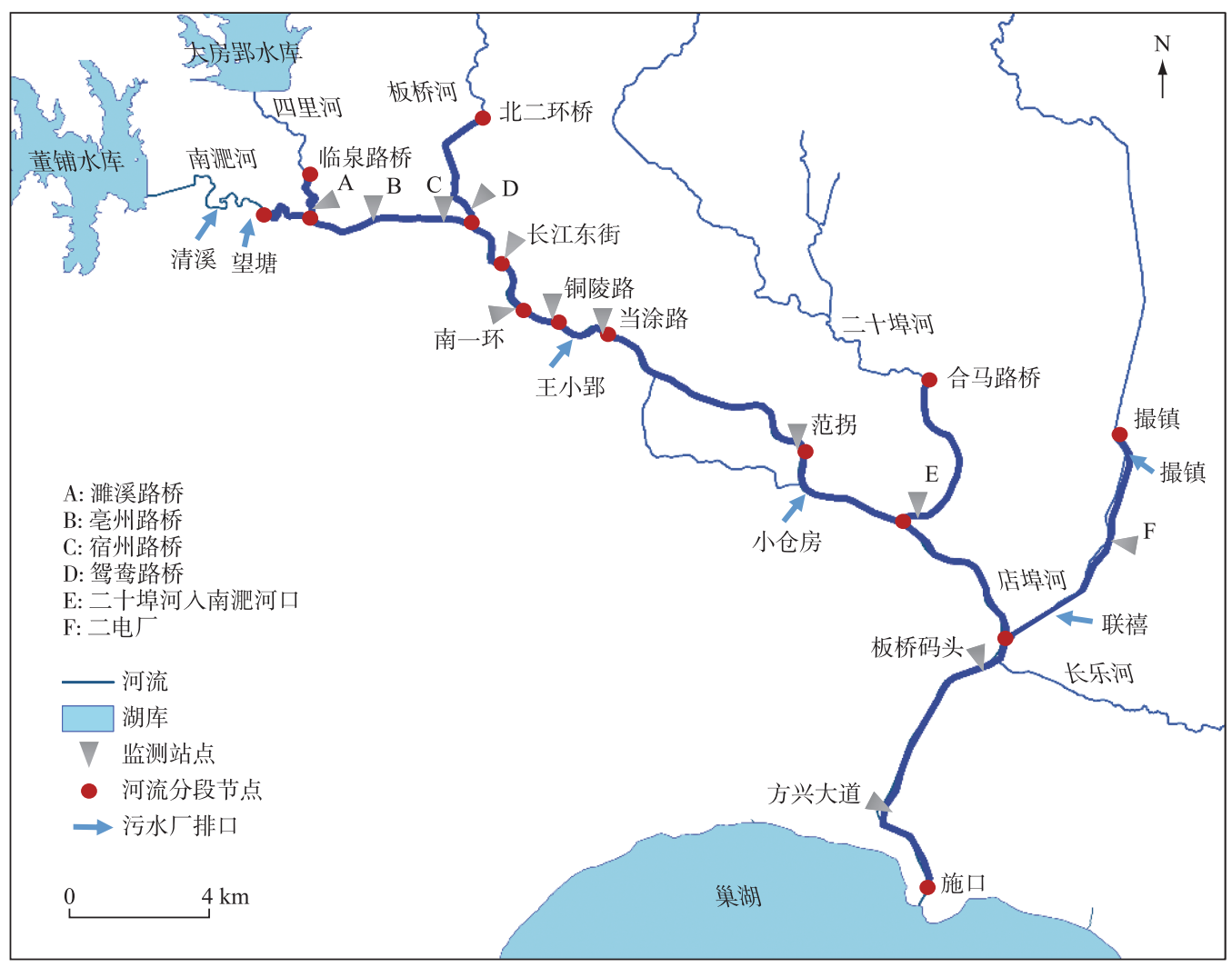

图 1 研究区南淝河水系及关键断面分布

Fig.1 The Nanfei River and the main gauging points

式中, $C$ 为某水质指标的浓度, $\mathrm{mg} / \mathrm{L} ; t$ 为时间, $\mathrm{s} ; D$ 为纵向离散系数, $\mathrm{m}^{2} / \mathrm{s} ; U$ 为断面平均流速, $\mathrm{m} / \mathrm{s} ; K$ 为某水 质指标的一阶衰减系数, $\mathrm{s}^{-1} ; S$ 为某水质指标的外部源汇项, $\mathrm{g} /\left(\mathrm{m}^{3} \cdot \mathrm{s}\right) ; x$ 为空间坐标.

水质数据同化的目标主要是通过实际观测水质浓度等数据和水质动态模型相互融合以达到提高模型 模拟和预测真实物理过程精度. 也就是在水质控制方程约束下, 寻找最优的控制变量 $P$ (模型初始条件、边 界条件和过程参数), 使表征模拟结果与观测差异的代价函数 $J$ 为最小, 即:

$$
\begin{gathered}
\min J(P)=\frac{1}{2} \int_{0}^{T}\left\|H \cdot C-C^{\mathrm{obs}}\right\|^{2} \mathrm{~d} t \\
\left\{\begin{array}{c}
F(C, P) \equiv \frac{\partial C}{\partial t}+\frac{\partial}{\partial x}\left(U \cdot C-D \frac{\partial C}{\partial x}\right)-S=0 \\
C(x, 0)=C_{0}, \text { 初始条件 } \\
\left.C\right|_{\partial \Omega}=C_{1}(t), \text { 第一类边界条件 } \\
\left.\frac{\partial C}{\partial x}\right|_{\partial \Omega}=0, \text { 第二类边界条件 }
\end{array}\right.
\end{gathered}
$$

式中, $T$ 为积分 (模拟) 时段; $H$ 为观测算子; $\partial \Omega$ 表示计算域的边界.

如果能计算出代价函数 $J$ 关于控制变量 $P$ 的梯度. 即可用梯度下降类方法求解优化求解代价函数极小 值. 变分同化法通过求解伴随方程来快速计算代价函数关于控制变量的梯度 ${ }^{[14]}$. 方程 (1) 的伴随方程可表 达为: 


$$
\left\{\begin{aligned}
-\frac{\partial C^{*}}{\partial t}-\frac{\partial U C^{*}}{\partial x}-\frac{\partial}{\partial x}\left(D \frac{\partial C^{*}}{\partial x}\right) & +H \cdot C-C^{\mathrm{obs}}+K-\frac{\partial S}{\partial C}=0 \\
C^{*}(T) & =0 \\
\left.\frac{\partial C^{*}}{\partial x}\right|_{\partial \Omega} & =0 \\
\left.C^{*}\right|_{\partial \Omega} & =0
\end{aligned}\right.
$$

原方程 (1), 伴随方程 (3) 和相应的初始、边界条件构成了双向的积分系统. 其即为一个关于控制变量 $P$ 的最优化控制系统 ${ }^{[17]}$. 利用最优化算法可实现该最优控制系统的求解, 即模拟得到与观测资料最为接近的 水质过程. 基于该最优化系统建立的模型即为水质变分同化模型. 本文建模采用了适用于大规模问题计算 的拟牛顿算法 L-BFGS ${ }^{[18]}$ 作为最优化算法,同化模型整体架构可参考文献 [17],这里不再赘述. 模型采用 Fortran 语言编码.

\section{2 南淝河模型构建}

根据南淝河的实际可用资料情况,模型计算范围设定为董铺水库以下 $5.3 \mathrm{~km}$ 至人湖口施口 ( 图 1 ), 模 拟干流段总长 $34.2 \mathrm{~km}$. 具体包括南泪河干流 (从望塘污水厂下游监测站开始至施口断面止)、四里河人河口 段 (临泉路)、板桥河人河口段 (北二环路桥)、二十埠河人河段 (合马路)、店埠河人口段 (撮镇). 河道模拟计 算分为 14 个河段,干流内部的分段节点分别为四里河人河口、板桥河人河口、长江东街、南一环、铜陵路、当 涂路、范拐、二十埠河人口以及店埠河人口. 各河段又划分成计算断面,各断面间距根据河道形态取 800 $1200 \mathrm{~m}$ 不等.

南淝河的水质计算边界主要包括干支流人流的水质浓度过程(第一类边界条件)、南淝河人湖口的自由 输出边界条件(第二类边界条件) 以及侧向污水处理厂和长乐河等支流的人流负荷边界条件. 人流浓度过程 包括干流上游、四里河临泉路、板桥河北二环路桥、二十埠河合马路和店埠河撮镇共 5 个边界水质指标浓度 过程.

人河负荷是水质计算的主要影响要素. 南淝河污染包括污水处理厂等排口以及地表漫流. 已知的污水 厂排口数据作为点源考虑, 包括计算区域内直接汇人干流的清溪、望塘、王小郢、小仓房以及汇人店埠河的 联喜和撮镇污水处理厂尾水. 对于一些小型排口及地表漫流, 其人河负荷情况难以掌握. 在本次计算中将这 些未知污染负荷计人非点源处理, 作为模型的控制变量, 通过变分同化模型进行识别计算, 解决了传统模型 若数据缺失则难以可靠模拟的问题.

模型的其他计算参数,如河流非恒定的水动力参数由水动力模型计算提供; 本次计算氨氮和总磷一阶 衰减系数 ${ }^{[19]}$ 分别取 0.06 和 $0.04 \mathrm{~d}^{-1}$.

\section{3 数据选用}

本文以氨氮和总磷作为代表性水质指标,模拟时段为 2019 年 10-12 月. 南泪河水质模拟的边界条件 和初始条件等数据根据自动监测站采集的逐日平均氨氮和总磷数据给定. 污水处理厂尾水排放数据也基于 逐日监测的过程数据. 模型同化观测资料来自于南佩河干流自动监测站,本次选用了方兴大道、板桥码头、 范拐、当涂路、铜陵路、南一环、长江东街、宿州路桥、毫州路桥、四里河濉溪路桥、板桥河然鲞路桥、二十埠河 人南汁河口、店埠河二电厂 (图 1 ) 等站的自动监测数据, 时间频次为 $\mathrm{d}$.

\section{3 结果分析与讨论}

\section{1 模拟结果}

采用模型分别计算了分散点源和面源人河污染负荷数据缺失条件下南淝河水质过程, 以及将这些非点 源负荷作为控制变量模拟的结果. 由于实际问题非线性强,迭代收玫性能受制约, 本次南淝河模拟经过 5000 次迭代,代价函数相对值从 1 降低至 0.416 ,降幅为 $59.4 \%$. 以此结果作为采用变分法得到的计算成果进行了 分析. 图 2 和图 3 展示了分散点源和面源人河污染负荷数据缺失条件下初始计算结果和采用变分法计算结 果与实际过程的比较.

从各监测断面水质过程来看, 若分散点源以及面源的人河数据缺失,计算得到各断面水质过程在长期 

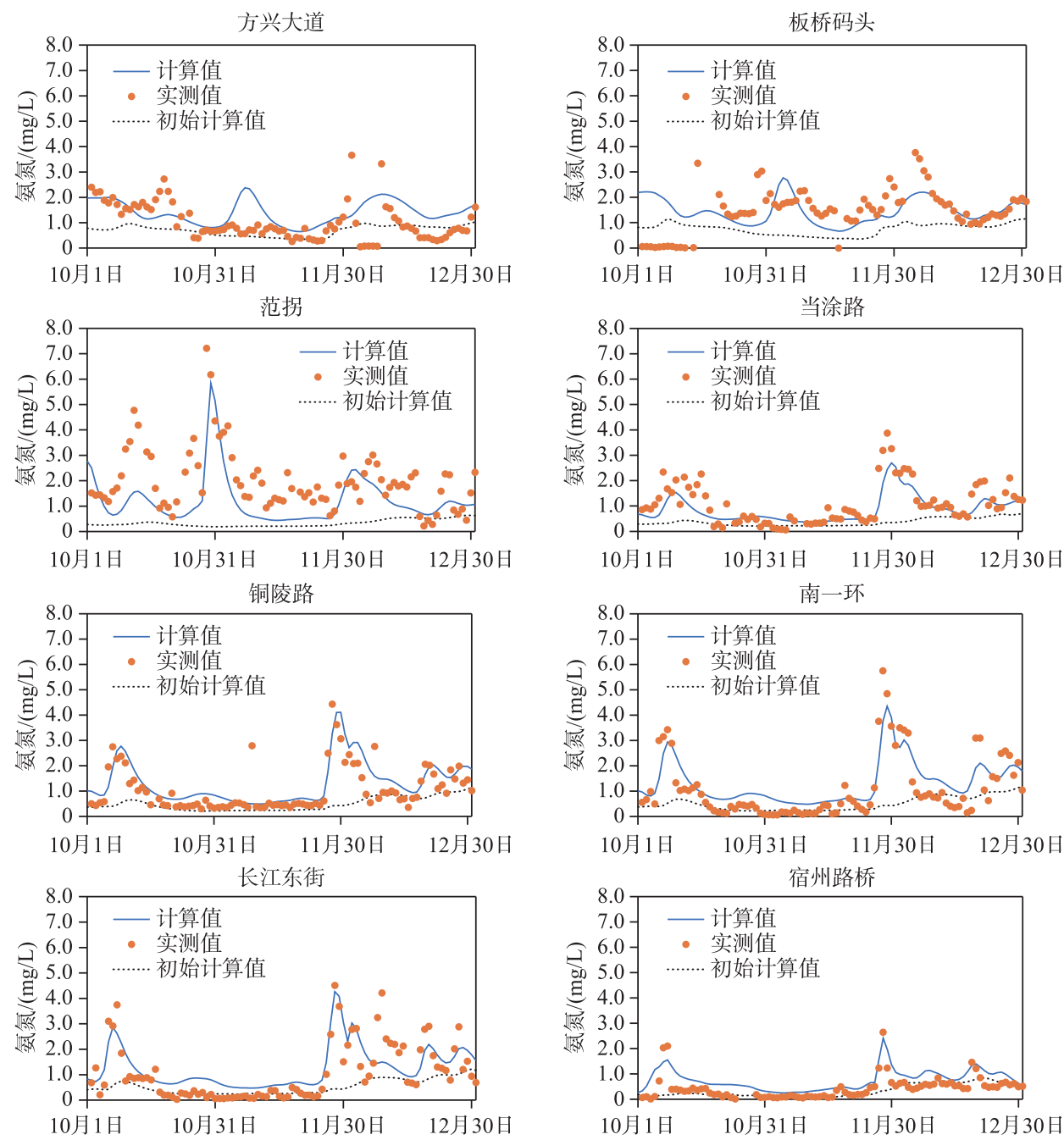

图 2 变分同化前后各站点氨氮过程线与实测值的比较

Fig.2 Comparison of measured ammonia nitrogen concentration hydrograph with the modeled ones before and after variational assimilation

无降雨时段 (11月), 当涂路以上站点的水质过程相对比较一致. 不过, 下游段, 特别是板桥码头和范拐断面 的计算值较实测值偏低, 说明在该河段内旱季也有污染汇人; 而方兴大道低估又有减少, 这可能和南浉河会 出现水流倒灌人河的情况有关. 在降雨影响的时段,计算结果偏差较大. 统计表明 (表 1), 各断面模拟结果 的均方根误差 (RMSE) 明显偏大, 纳什效率系数 $(N S E)$ 除个别断面个别指标外, 多数小于 0 . 这也说明, 南淝 河水质模拟仅考虑污水处理厂等尾水排放还不够. 受降雨影响的时段, 南汁河沿程仍有大量雨污水汇人南 汁河,造成南淝河的污染物浓度升高,水质变差,需对这些分散式的污染负荷加以考虑.

采用变分法同化观测数据后, 模拟得到的各断面水质过程计算结果得以大幅校正, 捕捉到了各个污染 指标波动的峰值, 较好地模拟了南淝河实际的水质变化过程. 虽然存在计算偏高和偏低等问题, 特别是范拐 断面的氨氮模拟结果偏低较为明显, 可能由于实际问题的复杂性限制, 使模型并没有收玫到理想状态. 但 是, 从总体来看, 计算结果均方根误差有明显下降. 氨氮 $R M S E$ 从各断面平均的 $1.03 \mathrm{mg} / \mathrm{L}$ 降至 $0.69 \mathrm{mg} / \mathrm{L}$, $N S E$ 则从平均-0.66 上升到 0.16 . 总磷 $R M S E$ 从各断面平均的 $0.07 \mathrm{mg} / \mathrm{L}$ 降至 $0.06 \mathrm{mg} / \mathrm{L}, N S E$ 则从平均 

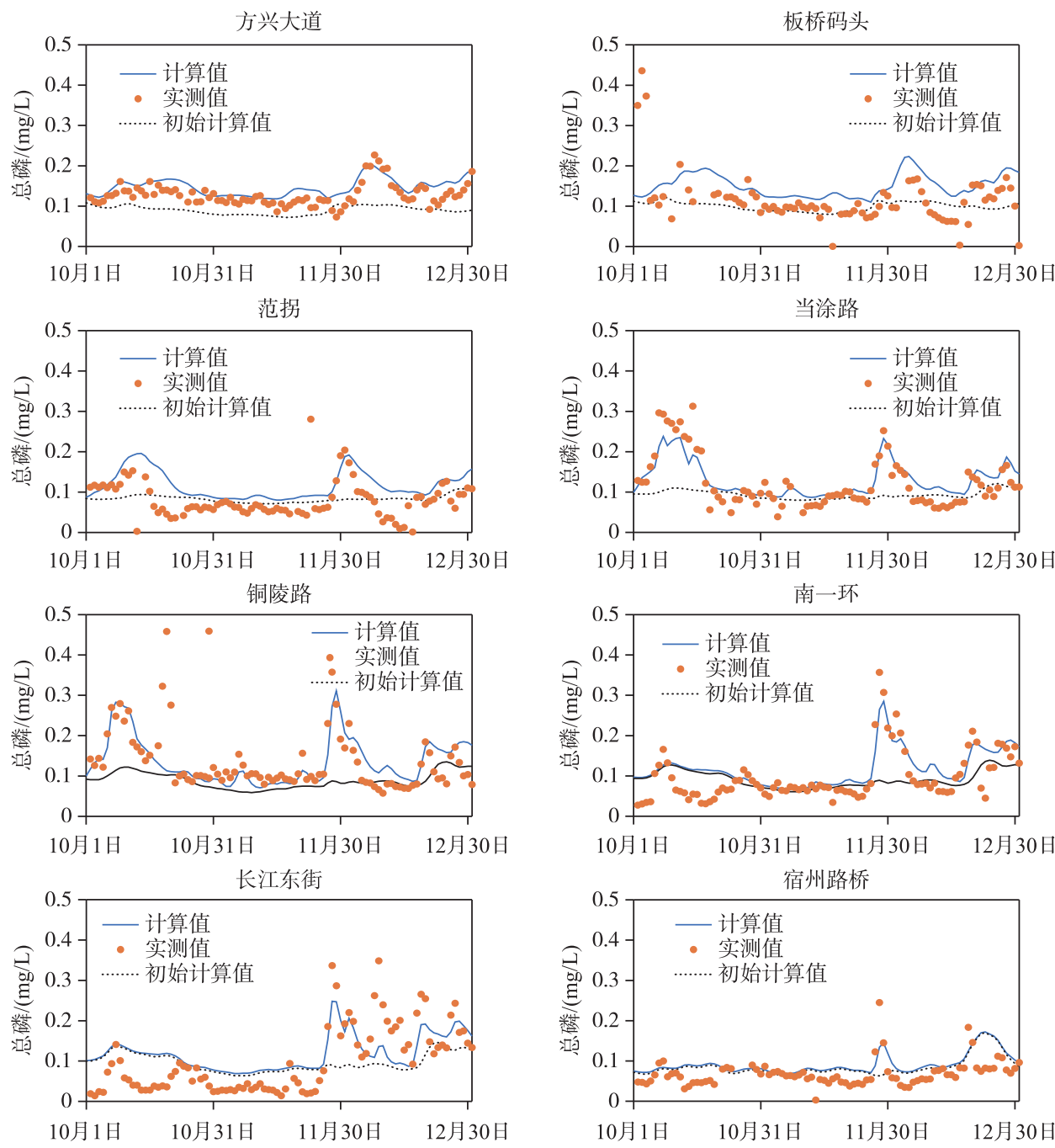

图 3 变分同化前后各站点总磷过程线与实测值的比较

Fig.3 Comparison of measured total phorsphorus concentration hydrograph with the modeled ones before and after variational assimilation

-1.50 上升到 -0.21 . 从各断面的各自变化来看, 干流长江东街到当涂路河段的水质模拟精度改进更为明显. 氨氮和总磷的 NSE 均从小于 0 分别提高至 0.62 和 0.50 . 下游施口、方兴大道等断面模拟精度较差, 可能与 巢湖水体出现倒流等因素有关.

\section{2 负荷识别结果}

本次模拟以人河非点源负荷作为控制变量, 采用变分同化模型模拟得到南淝河水质过程的同时, 也识 别得到了南淝河的人河非点源负荷过程. 各河段在模拟时段内 (10-12 月) 人河负荷总通量如图 4 所示. 南 汁河沿程各河段均有污染输人. 其中,氨氮负荷在当涂路一范拐河段、二十埠河人南淝河段、四里河口一板桥 河口河段、板桥河人南淝河河段以及南淝河人湖段均较高; 总磷负荷较高的河段则为南汁河人湖段、二十埠 河人南肥河段以及店埠河人南肥河段等. 通过同化不仅可得到各河段的负荷总通量数据,而且直接得到了 人河污染负荷通量随时间的变化过程. 这里选择南沜河人湖段以及当涂路一范拐河段的人河过程为例加以 说明模型的性能. 从图 5 中可以看出, 污染负荷随降雨过程的变化比较明显, 对应 10 月 5 日、11月 24-30 
表 1 变分同化前后各站点氨氮和总磷模拟计算精度比较

Tab.1 Modeling accuracy of ammonia nitrogen and total phosphorus before and after assimilation

\begin{tabular}{|c|c|c|c|c|c|c|c|c|c|c|}
\hline \multirow[b]{2}{*}{ 站点 } & \multicolumn{5}{|c|}{ 氨氮 } & \multicolumn{5}{|c|}{ 总磷 } \\
\hline & $\begin{array}{c}\text { 观测 } \\
\text { 均值/ } \\
\text { ( mg/L) }\end{array}$ & $\begin{array}{c}\text { 初始计算 } \\
R M S E / \\
(\mathrm{mg} / \mathrm{L})\end{array}$ & $\begin{array}{l}\text { 初始 } \\
\text { 计算 } \\
N S E\end{array}$ & $\begin{array}{c}\text { 变分计算 } \\
R M S E / \\
(\mathrm{mg} / \mathrm{L})\end{array}$ & $\begin{array}{l}\text { 变分 } \\
\text { 计算 } \\
N S E\end{array}$ & $\begin{array}{c}\text { 观测 } \\
\text { 均值/ } \\
(\mathrm{mg} / \mathrm{L})\end{array}$ & $\begin{array}{c}\text { 初始计算 } \\
R M S E / \\
(\mathrm{mg} / \mathrm{L})\end{array}$ & $\begin{array}{l}\text { 初始 } \\
\text { 计算 } \\
N S E\end{array}$ & $\begin{array}{c}\text { 变分计算 } \\
R M S E / \\
(\mathrm{mg} / \mathrm{L})\end{array}$ & $\begin{array}{l}\text { 变分 } \\
\text { 计算 } \\
N S E\end{array}$ \\
\hline 施口 & 1.60 & 1.05 & -3.44 & 0.69 & -0.87 & 0.19 & 0.11 & -13.06 & 0.06 & -2.91 \\
\hline 方兴大道 & 1.03 & 0.76 & -0.11 & 0.82 & -0.29 & 0.13 & 0.05 & -1.24 & 0.03 & 0.06 \\
\hline 板桥码头 & 1.48 & 1.14 & -0.56 & 1.00 & -0.21 & 0.13 & 0.10 & 0.03 & 0.11 & -0.20 \\
\hline 范拐 & 1.99 & 2.04 & -1.70 & 1.18 & 0.09 & 0.08 & 0.05 & 0.00 & 0.06 & -0.64 \\
\hline 当涂路 & 1.10 & 1.03 & -0.62 & 0.51 & 0.60 & 0.12 & 0.07 & -0.01 & 0.04 & 0.68 \\
\hline 铜陵路 & 1.06 & 0.98 & -0.32 & 0.58 & 0.54 & 0.13 & 0.08 & -0.28 & 0.06 & 0.32 \\
\hline 南一环 & 1.10 & 1.30 & -0.15 & 0.64 & 0.72 & 0.10 & 0.06 & -0.01 & 0.04 & 0.53 \\
\hline 长江东街 & 1.08 & 1.12 & -0.04 & 0.67 & 0.63 & 0.10 & 0.08 & 0.04 & 0.06 & 0.44 \\
\hline 宿州路桥 & 0.45 & 0.43 & 0.09 & 0.41 & 0.16 & 0.07 & 0.04 & -0.40 & 0.04 & -0.31 \\
\hline 毫州路桥 & 0.44 & 0.42 & 0.25 & 0.42 & 0.25 & 0.07 & 0.08 & -0.09 & 0.08 & -0.07 \\
\hline
\end{tabular}

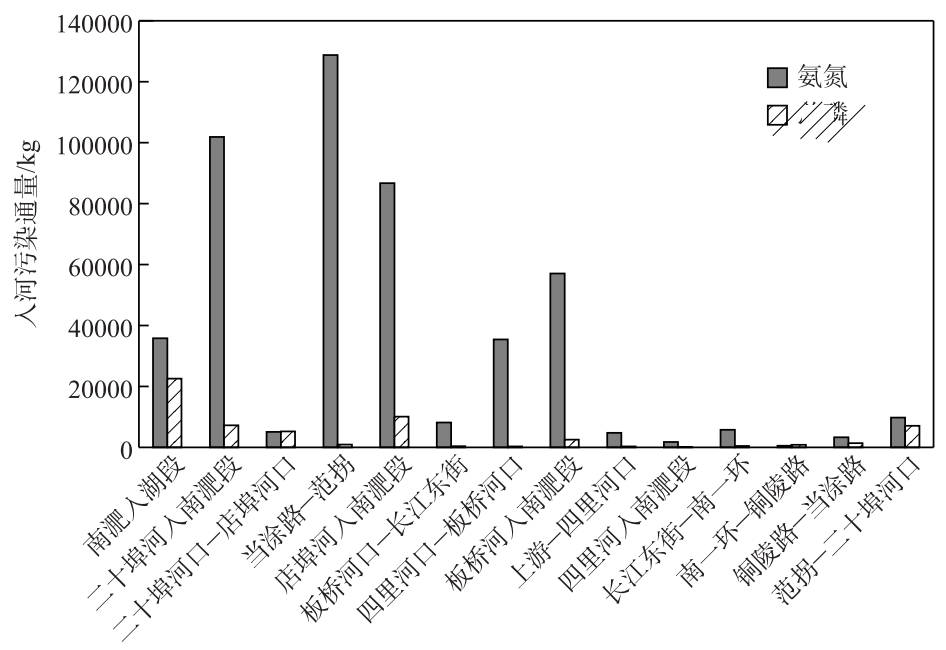

图 4 南汁河各河段识别的污染负荷

Fig.4 Identified pollutant loads in each reach of the Nanfei River
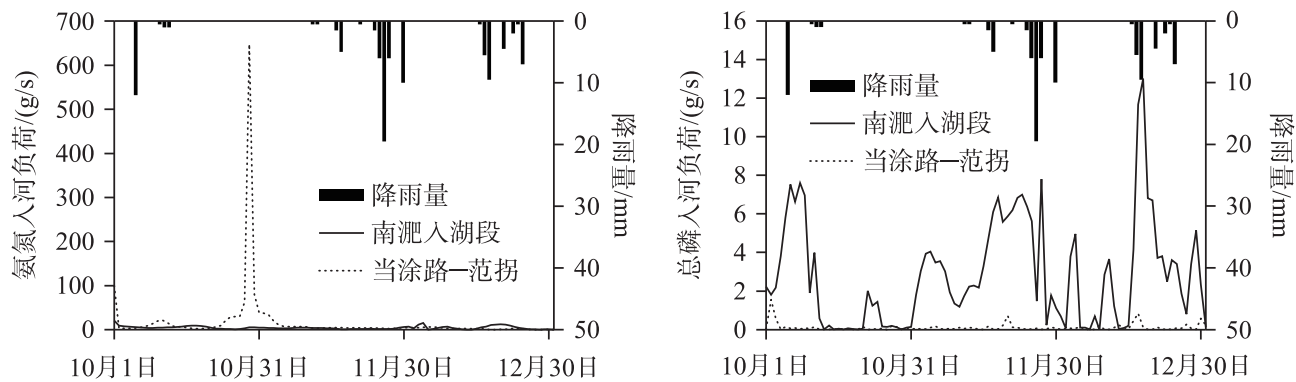

图 5 南淝河人湖段及当涂路一范拐河段的人河负荷过程

Fig.5 Hydrograph of pollutant loads in the two typical reaches and the corresponding rainfall during this period 
日以及 12 月 16-25 日每场降雨,各河段的氮、磷均可形成不同量级的负荷峰值. 说明降雨引起的雨污溢流 问题对南淝河水质有重要影响. 此外,本次计算还识别出了当涂路一范拐段河段 10 月末存在一个很高的氨 氮人河峰值, 为 $647.45 \mathrm{~g} / \mathrm{s}$. 虽然该负荷未知来源, 但是根据范拐及板桥码头断面在 10 月底出现的氨氮浓度 峰值, 可以确认这是合理的. 这也从侧面说明了该模型对未知的污染来源有很强的识别能力, 可在今后应用 于河流污染来源的定量追溯分析. 对于巢湖等流域人湖污染控制与河流水质预测预警具有重要价值.

\section{4 结论}

以巢湖流域南汁河干流为研究对象,基于变分同化方法构建了南淝河水质模型,模拟了 2019 年 10-12 月间南汁河干流及支流人河段的水质时空动态变化. 与实际观测数据以及基于已知污染负荷数据代人常规 模型模拟结果的对比分析表明:

1) 基于变分同化方法建立的南㲸河水质模型可模拟人河污染负荷数据缺失条件下南洞河水质过程, 成 功捕捉水质波动变化的不同峰值, 水质浓度模拟精度明显改进. 该方法为缺资料地区河流模拟提供了可能 的手段.

2 ) 模型在计算水质过程的同时,也得到了南淝河各河段的人河负荷动态变化过程,为河流水质污染溯 源及成因分析提供了定量数据支持. 模拟结果表明, 本文提出的方法对人河污染敏感, 可用于关键河段污染 定量溯源, 可支撑巢湖等流域复杂河流的人湖污染控制.

3 ) 基于变分同化法的水质模拟通过同化河道内水质指标浓度观测数据,代替常规模型需要以人河污染 负荷数据作为输人条件的应用前提. 亦即以河道内的浓度观测数据作为输人条件代替污染人河负荷作为输 人条件, 避开了人河负荷准确估算的难点, 使得在复杂环境条件下河流水质模拟更为可靠. 南淝河的水质模 拟研究展现了该模型在复杂环境条件下的应用潜力,对流域河流水质预测预警及污染管控具有重要意义.

\section{5 参考文献}

[ 1 ] EPA. Guidance on the development, evaluation, and application of environmental models. US Environmental Protection Agency, 2009. EPA/100/K-09/003.

[ 2 ] Lai XJ. A review of integrated water quality modeling for a watershed. Progress in Geography, 2019, 38(8) : 1123-1135. [赖锡军. 流域水环境过程综合模拟研究进展. 地理科学进展, 2019, 38(8): 1123-1135.]

[ 3 ] Loucks DP, van Beek E. Water quality modeling and prediction. In: Loucks DP, van Beek E eds. Water resource systems planning and management: An introduction to methods, models, and applications. Cham: Springer International Publishing, 2017: 417-467.

[ 4 ] Zou XL. Four-dimensional variational data assimilation. Atmospheric Satellite Observations. Amsterdam: Elsevier, 2020: 163-174. DOI: 10.1016/b978-0-12-820950-9.00009-x.

[ 5 ] Fletcher SJ. Applications of data assimilation in the geosciences. Data Assimilation for the Geosciences. Amsterdam: Elsevier, 2017: 887-916. DOI: 10.1016/b978-0-12-804444-5.00023-4.

[ 6 ] Janeković I, Mihanović H, Vilibić I et al. Using multi-platform 4D-Var data assimilation to improve modeling of Adriatic Sea dynamics. Ocean Modelling, 2020, 146: 101538. DOI: 10.1016/j.ocemod.2019.101538.

[ 7 ] Ghorbanidehno H, Kokkinaki A, Lee J et al. Recent developments in fast and scalable inverse modeling and data assimilation methods in hydrology. Journal of Hydrology, 2020, 591: 125266. DOI: 10.1016/j.jhydrol.2020.125266.

[ 8 ] Honnorat M, Monnier J, Dimet FX. Lagrangian data assimilation for river hydraulics simulations. Computing and Visualization in Science, 2009, 12(5) : 235-246. DOI: 10.1007/s00791-008-0089-x.

[ 9 ] Lai X, Liang Q, Yesou H et al. Variational assimilation of remotely sensed flood extents using a 2-D flood model. Hydrology and Earth System Sciences, 2014, 18(11) : 4325-4339. DOI: 10.5194/hess-18-4325-2014.

[10] Cho KH, Pachepsky Y, Ligaray M et al. Data assimilation in surface water quality modeling: A review. Water Research, 2020, 186: 116307. DOI: 10.1016/j.watres.2020.116307.

[11] Shao DG, Wang ZM, Wang B et al. A water quality model with three dimensional variational data assimilation for contaminant transport. Water Resources Management, 2016, 30(13) : 4501-4512. DOI: 10.1007/s11269-016-1432-5.

[12] Babbar-Sebens M, Li L, Song K et al. On the use of Landsat-5 TM satellite for assimilating water temperature observations 
in 3D hydrodynamic model of small inland reservoir in Midwestern US. Advances in Remote Sensing, 2013, 2: 214-227.

[13] Lawless AS. Variational data assimilation for very large environmental problems. Large Scale Inverse Problems: Computational Methods and Applications in the Earth Sciences, 2013, 13: 55-90.

[14] LeDimet FX, Talagrand O. Variational algorithms for analysis and assimilation of meteorological observations: Theoretical aspects. Tellus A: Dynamic Meteorology and Oceanography, 1986, 38(2) : 97-110. DOI: 10.3402/tellusa.v38i2.11706.

[15] Zhang M, Kong FX. The process, spatial and temporal distributions and mitigation strategies of the eutrophication of Lake Chaohu (1984-2013). J Lake Sci, 2015, 27(5) : 791-798. DOI : 10.18307/2015.0505. [张民, 孔繁翔. 巢湖富营养 化的历程、空间分布与治理策略(1984-2013 年). 湖泊科学, 2015, 27(5): 791-798.]

[16] Zhang D, Tian X, Wu S. Analysis of pollution flux in Nanfeihe River and its treatment. Water Resources Protection, 2020 : 1-6. [张笛，田釒金，吴师. 南淝河污染通量解析与治理. 水资源保护，2020: 1-6.]

[17] Lai XJ, Fu GS, Sun B. Optimal control problems in unsteady flow computation and their variational solutions. Advances in Water Science, 2008, 19(4): 537-545. [赖锡军, 傅国圣, 孙波. 非恒定水流计算的最优控制问题及其变分求解. 水 科学进展, $2008,19(4): 537-545$.]

[18] Gilbert JC, Lemaréchal C. Some numerical experiments with variable-storage quasi-Newton algorithms. Mathematical Programming, 1989, 45(1/2/3) : 407-435. DOI: 10.1007/BF01589113.

[19] Feng S, Li XY, Deng JC. Determination of comprehensive pollutants attenuation coefficients of the plain river networks in the upper reaches of Lake Taihu Basin. Acta Scientiae Circumstantiae, 2017, 37(3) : 878-887. DOI: 10.13671/j.hjkxxb. 2016.0125. [冯帅, 李叙勇, 邓建才. 太湖流域上游平原河网污染物综合衰减系数的测定. 环境科学学报, 2017, 37(3) : 878-887.] 